\title{
Complications and outcomes of routine endoscopy in the very elderly
}

\section{(ㄷ)(잉}

Authors

Ryoichi Miyanaga', Naoki Hosoe², Makoto Naganuma', Kenro Hirata', Seiichiro Fukuhara², Yoshihiro Nakazato², Keisuke Ojiro ${ }^{2}$, Eisuke Iwasaki ${ }^{1}$, Naohisa Yahagi ${ }^{3}$, Haruhiko Ogata², Takanori Kanai ${ }^{1}$

Institutions

1 Division of Gastroenterology and Hepatology, Department of Internal Medicine, School of Medicine, Keio University, Tokyo, Japan.

2 Center for Diagnostic and Therapeutic Endoscopy, School of Medicine, Keio University, Tokyo, Japan.

3 Division of Research and Development for Minimally Invasive Treatment, Cancer Center, School of Medicine, Keio University, Tokyo, Japan.

submitted 22.10.2016

accepted after revision 17.7.2017

\author{
Bibliography \\ DOI https://doi.org/10.1055/s-0043-120569 | \\ Endoscopy International Open 2018; 06: E224-E229 \\ (C) Georg Thieme Verlag KG Stuttgart · New York \\ ISSN 2364-3722
}

Corresponding author

Takanori Kanai, MD, PhD, Division of Gastroenterology and Hepatology, Department of Internal Medicine, School of Medicine, Keio University, 35 Shinanomachi, Shinjuku,

Tokyo 160-8582, Japan

Fax: +81-3-3357-2778

takagast@z2.keio.jp

\section{ABSTRACT}

Background and study aims In Japan, the elderly population has been increasing annually. The number of elderly patients for whom esophagogastroduodenoscopy (EGD) and colonoscopy (CS) is indicated also has been rising. The aim of this study was to evaluate the safety and efficacy of routine endoscopy in a cohort of octogenarians aged 85 years and older - defined by the World Health Organization as the very elderly.

Patients and methods A total of 5,586 patients underwent EGDs, and 2,484 patients underwent CSs performed at the Keio University Hospital from January to September 2014. One hundred eighty-five EGDs and 70 of the CS were performed in the very elderly. Six hundred nine EGDs and 262 CS were performed on younger patients (aged forties). Statistical analysis was performed by univariate and multivariate analyses.

Results On univariate analysis, the rate of adverse events (AEs) in the very elderly was significantly higher compared to the younger group ( $6.3 \%$ vs. $1.1 \% ; P<0.01$ ). Moreover, the very elderly cohort received substantial therapeutic intervention as compared to the younger ( $16.9 \%$ vs. $6.9 \%$; $P<0.01)$. On multivariate analysis, independent risk factors of AEs included: very elderly patients (odds ratio (OR) 3.30, $95 \%$ confidence interval $(\mathrm{Cl}) 1.05-10.35$ ), inpatients (OR $3.22,95 \% \mathrm{Cl} 1.34-7.74)$, and use of pethidine hydrochloride prescription (OR 3.44, $95 \% \mathrm{Cl} 1.51-7.81$ ).

Conclusions Routine endoscopy in the very elderly incurs a significant risk of AEs, particularly when combined with pethidine hydrochloride prescription.

\section{Introduction}

In recent years, Japan's aging population has surged to unprecedented levels. A 2015 census of the very elderly (85 years and older) exceeded 4.9 million (3.9\%) [1]. According to the 2013 World Health Organization Report, life expectancy has increased throughout most parts of the world [2]. The incidence of gastrointestinal disease, particularly gastrointestinal cancers, inevitably increases with age [3-5]. Based on a report issued by the US National Cancer Institute, 21.6 and 192.6 pa- tients per 100,000 diagnosed with esophageal and colorectal cancers, respectively, were aged 65 and over [6]. Besides malignant diseases, elderly patients tend to present with benign diseases such as gastrointestinal ulcers [7]. As a result, the number of elderly patients for whom esophagogastroduodenoscopy (EGD) and colonoscopy (CS) are indicated has been increasing in both Japan and western countries [8,9].

By comparison, the complication rate for endoscopy is reported to be lower in younger patients; however, EGD and CS tend to induce cardiac and respiratory stress in elderly patients 


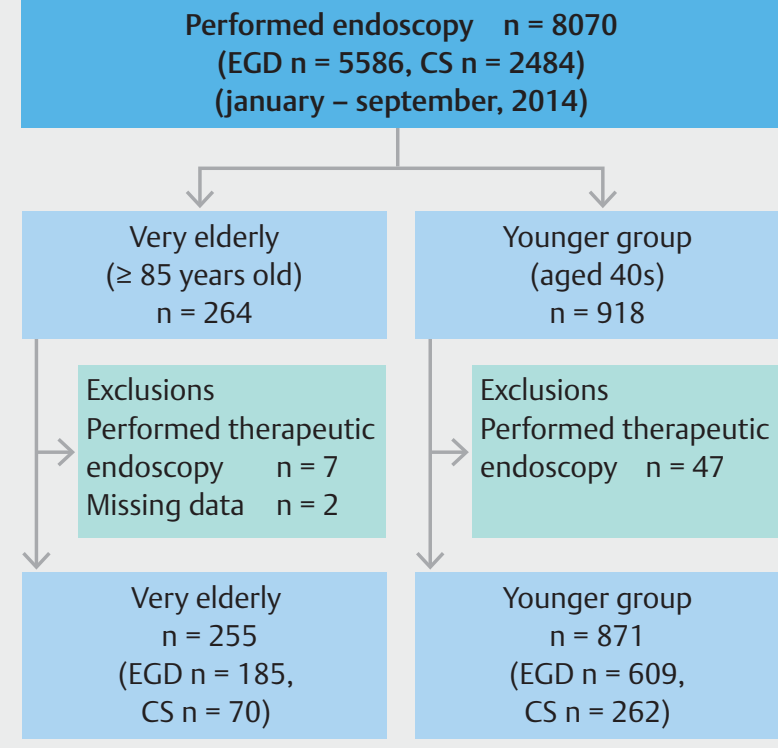

- Fig. 1 Flowchart of enrolled patients. EGD, esophagogastroduodenoscopy; CS, colonoscopy.

$[10,11]$. To date, cohort study data have been insufficient for assessing the safety and efficacy of endoscopy in the elderly $[4,12-16]$, particularly studies reporting on the very elderly population (85 years and older) $[17,18]$. The safety and efficacy of both EGD and CS remain unconfirmed within the literature. To that end, this study aimed to evaluate the safety and efficacy of EGD and CS in the very elderly in routine clinical practice.

\section{Patients and methods}

\section{Study design}

In a retrospective case-control study approved by the ethics committee of Keio University Hospital, data were collected from medical charts and the details of endoscopy findings were obtained using an Endoscopy Reporting System (Solemio ENDO, Olympus, Tokyo, Japan). Patients undergoing EGD or CS without scheduled therapeutic endoscopy from January to September 2014 at Keio University Hospital were screened. Among those screened, the very elderly (aged $\geq 85$ years) were defined as cases and patients aged forties were defined as controls ( Fig. 1).

We evaluated risk and efficacy parameters for EGD and CS based on the following data systematically collected from medical charts and endoscopy reports of the very elderly and younger group including: (1) gender; (2) age; (3) endoscopy naive/non-naive patients; (4) type of endoscopy (EGD or CS); (5) inpatient or outpatient; (6) comorbidity; (7) daily medication(s); (8) pre-endoscopic medication; (9) therapeutic intervention post-routine endoscopy; and (10) endoscopy-associated AEs. For routine endoscopy, some of the following pre-endoscopic medications were used intravenously: $1 \mathrm{U}$ glucagon,
$0.2 \mathrm{mg}$ of flunitorazepam, $35 \mathrm{mg}$ of pethidine hydrochloride, and $2.5 \mathrm{mg}$ of midazolam. Based on results of routine endoscopy, modifications to therapeutic interventions were required, such as drug administration (i. e. proton pump inhibitor), endoscopic therapy (endoscopic variceal ligation [EVL], endoscopic injection sclerotherapy [EIS], endoscopic mucosal resection [EMR], endoscopic submucosal dissection [ESD], open surgery, chemotherapy, or radiation therapy). AEs were defined as hypotension (systolic blood pressure $\leq 80 \mathrm{mmHg}$ ), hypoxemia $\left(\mathrm{SpO}_{2}\right.$ $<90 \%$ in ambient air and needed additional oxygen), digestive symptoms (needed X-ray, blood test or administered any additional drip injection for abdominal pain, nausea and vomiting), bleeding required for endoscopic hemostasis, perforation, and endoscopy-related death. Vital signs were monitored during the pre-procedure and every 5 minutes during the procedures.

\section{Statistical analysis}

Statistical analyses were performed using Student's $t$-test for normally distributed continuous variables, the Mann-Whitney $\mathrm{U}$ test for non-normally distributed continuous variables, and the chi-square test for non-continuous variables. To identify parameters influencing AEs associated with EGD and CS, we examined potential factors using univariate analysis. After determining the relevant risk factors $(P$ values $<0.05)$ in the univariate analysis, they were subsequently entered into a multivariate analysis using a binary logistic regression model. Odds ratios (OR) and corresponding $95 \%$ confidence intervals $(\mathrm{Cl})$ were generated for all variables. $P$ values $<0.05$ were considered significant. Significant parameters were multivariate analysed by univariate analysis. PASW version 22 software (SPSS Inc., Tokyo, Japan) was used for all statistical analyses.

\section{Results}

- Fig. 1 shows a flowchart of enrolled patients. From January to September 2014, 5,586 and 2,484 patients underwent EGD and CS procedures, respectively. The very elderly in this cohort underwent 188 EGD procedures and 76 CS procedures. Furthermore, the control group underwent 609 EGD and 262 CS procedures, respectively. Excluded from the data set were 56 endoscopy procedures (scheduled therapeutic endoscopy, 54; missing data, 2). In total, our analysis included 255 procedures in the very elderly group (EGD 185, CS 70), and 871 procedures (EGD 609, CS 262) in the younger group. Profiles of enrolled patients are shown in $\downarrow$ Table 1 and include gender ratio, rate of initial procedure, outpatient to inpatient ratio, and comorbidity. A significant difference between groups was observed for patients designated as "medication without tranquilizers." Moreover, because the rate of comorbidities was higher in the very elderly group, more medications were used in them than in the younger group. $>$ Table 2 shows the pre-endoscopic medications for the 2 groups. There was a significantly higher rate of glucagon administration in the very elderly group. By comparison, the younger group were more likely to receive flunitorazepam and midazolam. In particular, there was a significantly higher rate of pethidine hydrochloride administration to the younger CS group. The very elderly group also received 
- Table 1 Characteristics of the study groups.

\begin{tabular}{|c|c|c|c|}
\hline & Very elderly & Younger group & $P$ value \\
\hline Number of patients ( $n$ ) & 255 & 871 & \\
\hline Male/female (n/n) & $156 / 99$ & $437 / 434$ & $<0.01$ \\
\hline Mean age (min-max) & $87.4(85-97)$ & $40.5(17-49)$ & $<0.01$ \\
\hline Initial procedure, n (\%) & $21(8.2 \%)$ & $229(26.3 \%)$ & $<0.01$ \\
\hline $\mathrm{EGD} / \mathrm{CS}(\mathrm{n} / \mathrm{n})$ & $185 / 70$ & $609 / 262$ & 0.42 \\
\hline Outpatient/inpatient (n/n) & $190 / 65$ & $778 / 93$ & $<0.01$ \\
\hline \multicolumn{4}{|l|}{ Comorbidity } \\
\hline - Respiratory disease, n (\%) & $46(18.0 \%)$ & $65(7.5 \%)$ & $<0.01$ \\
\hline - Hypertension, n (\%) & $168(65.9 \%)$ & $77(8.8 \%)$ & $<0.01$ \\
\hline - Cardiovascular disease, n (\%) & $104(40.8 \%)$ & $45(5.2 \%)$ & $<0.01$ \\
\hline - Cerebrovascular disease, n (\%) & $32(12.5 \%)$ & $5(0.6 \%)$ & $<0.01$ \\
\hline - Malignancy (Post-therapy inclusion), n (\%) & $118(46.3 \%)$ & $153(17.6 \%)$ & $<0.01$ \\
\hline - Diabetes mellitus, $\mathrm{n}(\%)$ & $43(16.9 \%)$ & $34(3.9 \%)$ & $<0.01$ \\
\hline - Abdominal surgical history, n (\%) & $76(29.8 \%)$ & $126(14.4 \%)$ & $<0.01$ \\
\hline \multicolumn{4}{|l|}{ Medications } \\
\hline - Antihypertensive drug, n (\%) & $163(63.9 \%)$ & $64(7.3 \%)$ & $<0.01$ \\
\hline - Antithrombotic drug, n (\%) & $109(42.7 \%)$ & $30(3.4 \%)$ & $<0.01$ \\
\hline - Hypoglycemic drug, n (\%) & $27(10.6 \%)$ & $30(3.4 \%)$ & $<0.01$ \\
\hline - Tranquilizer, n (\%) & $30(11.8 \%)$ & $86(9.9 \%)$ & 0.38 \\
\hline
\end{tabular}

- Table 2 Pre-endoscopic medications.

\begin{tabular}{|c|c|c|c|}
\hline & Very elderly & Younger group & $P$ value \\
\hline Esophagogastroduodenoscopy, n (\%) & $185(100 \%)$ & $609(100 \%)$ & \\
\hline - Glucagon, n (\%) & $102(55.1 \%)$ & $52(8.5 \%)$ & $<0.01$ \\
\hline - Flunitorazepam, n (\%) & $106(57.3 \%)$ & $456(74.9 \%)$ & $<0.01$ \\
\hline - Pethidine hydrochloride, n (\%) & $3(1.6 \%)$ & $17(2.7 \%)$ & 0.37 \\
\hline - Midazolam, n (\%) & $7(3.8 \%)$ & $132(21.7 \%)$ & $<0.01$ \\
\hline Colonoscopy, n (\%) & $70(100 \%)$ & $262(100 \%)$ & \\
\hline - Glucagon, n (\%) & $52(74.3 \%)$ & $19(7.3 \%)$ & $<0.01$ \\
\hline - Flunitorazepam, n (\%) & $2(2.9 \%)$ & $37(14.1 \%)$ & $<0.01$ \\
\hline - Pethidine hydrochloride, n (\%) & $48(68.6 \%)$ & $241(92.0 \%)$ & $<0.01$ \\
\hline - Midazolam, n (\%) & $1(0.5 \%)$ & $6(2.3 \%)$ & 0.66 \\
\hline
\end{tabular}

therapeutic interventions more frequently post-routine endoscopy as compared to the younger group (16.1\% vs. $6.9 \% P<$ 0.01, Table 3). Therapeutic interventions were mainly drug administration and endoscopic procedures in both groups. - Table 4 shows incidence and types of AEs of routine endoscopy. As indicated in the table, incidence of AEs in the very el- derly patient group was significantly higher compared to that in younger patients $(6.3 \%$ vs. $1.1 \% ; P<0.01)$. The most common AE observed in the both groups was hypoxemia and the second was severe abdominal symptoms. Severe AEs such as bleeding, perforation and death were not observed in either group. 
- Table 3 Therapeutic interventions post-routine endoscopy.

\begin{tabular}{|c|c|c|c|}
\hline & Very elderly & Younger group & $P$ value \\
\hline Total number of patients, $\mathrm{n}(\%)$ & $43(16.9 \%)$ & $60(6.9 \%)$ & $<0.01$ \\
\hline - Drug administration, n (\%) & $14(5.5 \%)$ & $15(1.7 \%)$ & \\
\hline - EVL and / or EIS, n (\%) & $1(0.4 \%)$ & $5(0.6 \%)$ & \\
\hline - APC, n (\%) & $3(1.2 \%)$ & $0(0 \%)$ & \\
\hline - EMR, n (\%) & $16(6.3 \%)$ & $32(3.7 \%)$ & \\
\hline - ESD, n (\%) & $4(1.5 \%)$ & $2(0.2 \%)$ & \\
\hline - Open surgery, n (\%) & $2(0.8 \%)$ & $4(0.8 \%)$ & \\
\hline - Chemo and/or radiation therapy, n (\%) & $2(0.8 \%)$ & $0(0 \%)$ & \\
\hline - Others & $2(0.8 \%)$ & $2(0.2 \%)$ & \\
\hline $\begin{array}{l}\text { EVL, endoscopic variceal ligation; EIS, endosco, } \\
\text { submucosal dissection } \\
\text { Excluded eradication of Helicobacter pylori } \\
\text { Others include endoscopic ballooning (very eld } \\
\text { One patient in very elderly group got EVL and }\end{array}$ & $\begin{array}{l}\text { lasma coagulatio } \\
\text { ransplantation b }\end{array}$ & $\begin{array}{l}\text { loscopic mucosal res } \\
\text { ukemia (control 1). }\end{array}$ & endoscopic \\
\hline
\end{tabular}

- Table4 Incidence and type of adverse events associated with routine endoscopy.

\begin{tabular}{|l|l|l|}
\hline & Very elderly & Younger group \\
\hline Total number of adverse events, $\mathrm{n}(\%)$ & $16(6.3 \%)$ & $11(1.1 \%)$ \\
\hline - Hypotension, $\mathrm{n}(\%)$ & $2(0.8 \%)$ & $2(0.2 \%)$ \\
\hline - Hypoxemia, $\mathrm{n}(\%)$ & $9(3.5 \%)$ & $7(0.8 \%)$ \\
\hline - Severe abdominal symptoms, $\mathrm{n}(\%)$ & $5(2.0 \%)$ & $4(0.5 \%)$ \\
\hline - Bleeding, $\mathrm{n}(\%)$ & $1(0.4 \%)$ & $0(0 \%)$ \\
\hline - Perforation, $\mathrm{n}(\%)$ & $0(0 \%)$ & $0(0 \%)$ \\
\hline - Death, $\mathrm{n}(\%)$ & $0(0 \%)$ & $0(0 \%)$ \\
\hline
\end{tabular}

Results of univariate and multivariate analysis, including parameters affecting AEs, are shown in $>$ Table 5 . In univariate analysis, 5 parameters including very elderly age, inpatient status, comorbidity of cardiovascular disease, and administration of glucagon and pethidine hydrochloride were significant factors for risk of AEs associated with routine endoscopy. In multivariate analysis, 3 of 5 parameters, including very elderly age, inpatient status, and administration of pethidine hydrochloride were associated with risk of AEs for routine endoscopy. Pethidine hydrochloride administration was the most significant of the 3 parameters (OR $3.44,95 \% \mathrm{Cl} 1.51-7.81, P<0.01$ ).

\section{Discussion}

We evaluated safety and efficacy of endoscopy in a routine clinical setting targeting the upper bracket of the elderly population. In the current cohort, very elderly Japanese patients had multiple comorbidities and received numerous medications. By comparison, an American population-based study reported that severe AEs (colonic perforations and gastrointestinal bleeding) with outpatient colonoscopy were associated with chronic and multiple comorbidities in the elderly [3]. However, in our multivariate analysis, even though comorbidity was not an independent predictive factor for AEs, cardiovascular disease showed a trend toward risk complications $(P=0.15)$.

In the current study, the rate of AEs in the very elderly was $6.3 \%$, greater than that in the younger group, observed at $1.1 \%$. In another study, Clarke et al. [17] conducted a singlearm observational study of 214 consecutive participants who underwent endoscopic procedures including EGD, CS and endoscopic retrograde cholangiopancreatography (ERCP), including patients aged 85 years and older. Ten percent of the time, the procedures were performed by emergency care as a result of upper gastrointestinal hemorrhage. In contrast, we recruited the elective cohort without therapeutic procedures nor emergency care in routine clinical practice. The authors of the aforementioned study also reported no procedure-related mortality, rates of colonic perforation and of cardiopulmonary complications in sedated patients were $0.1 \%$ and $0.6 \%$, respectively. They concluded that gastrointestinal endoscopy in the very elderly is an extremely safe procedure. Comparatively, our results show no procedure-related mortality, non-existent per- 
- Table 5 Predictors of adverse events associated with routine endoscopy.

\begin{tabular}{|c|c|c|c|c|c|}
\hline \multirow[b]{2}{*}{ Parameters } & \multicolumn{2}{|c|}{ Univariate analysis } & \multicolumn{3}{|c|}{ Multivariate analysis } \\
\hline & OR & $P$ value & OR & $\mathrm{Cl}(95 \%)$ & $P$ value \\
\hline Male & 0.77 & 0.50 & & & \\
\hline Age ( $\geq 85$ years) & 4.89 & $<0.01$ & 3.30 & $1.05-10.35$ & 0.04 \\
\hline Initial endoscopy & 1.58 & 0.29 & & & \\
\hline EGD procedure & 0.48 & 0.59 & & & \\
\hline Inpatient & 5.60 & $<0.01$ & 3.22 & $1.34-7.74$ & $<0.01$ \\
\hline \multicolumn{6}{|l|}{ Comorbidity } \\
\hline - Respiratory disease & 2.23 & 0.27 & & & \\
\hline - Hypertension & 1.33 & 0.52 & & & \\
\hline - Cardiovascular disease & 5.11 & $<0.01$ & 2.13 & $0.17-1.31$ & 0.15 \\
\hline - Cerebrovascular disease & 0.00 & 0.34 & & & \\
\hline - Malignancy & 0.71 & 0.42 & & & \\
\hline - Diabetes mellitus & 1.13 & 0.86 & & & \\
\hline - Abdominal surgical history & 1.09 & 0.86 & & & \\
\hline \multicolumn{6}{|l|}{ Medications } \\
\hline - Antihypertensive drug & 1.47 & 0.38 & & & \\
\hline - Antithrombotic drug & 2.18 & 0.09 & & & \\
\hline - Hypoglycemic drug & 0.74 & 0.78 & & & \\
\hline - Tranquilizer & 0.34 & 0.27 & & & \\
\hline \multicolumn{6}{|l|}{ Pre-endoscopic medication } \\
\hline - Glucagon & 3.04 & $<0.01$ & 1.23 & $0.29-2.31$ & 0.70 \\
\hline - Flunitorazepam & 0.74 & 0.46 & & & \\
\hline - Pethidine hydrochloride & 2.97 & $<0.01$ & 3.44 & $1.51-7.81$ & $<0.01$ \\
\hline - Midazolam & 0.55 & 0.42 & & & \\
\hline
\end{tabular}

foration, and a slightly higher rate of cardiopulmonary complications (hypoxemia, 3.5\%; hypotension, $0.8 \%$ ). These differences arose from the observed cohort and how AEs were defined. Furthermore, three separate studies $[4,15,18]$ have confirmed the safety of colonoscopy in elderly populations. Day et al. [19] conducted a meta-analysis reporting that elderly patients, particularly octogenarians, appear to have a higher risk of complications both during and after colonoscopy. Our results suggest that the very elderly incurs some complications in routine endoscopy, especially hypoxemia; however, procedure-related mortality was not observed in this study.

We subsequently calculated independent variables potentially influencing AEs in routine endoscopy using logistic multivariate analysis. These variables included age $\geq 85$ years, inpatient status, and administration of pethidine hydrochloride as risk factors for $\mathrm{AE}$ associated with routine endoscopy. Results of our multivariate analysis indicate that in the very elderly, routine endoscopy carries various risk factors. Inpatients undergoing endoscopic examination may have more unmeasured risk factors than outpatients. In particular, administration of pethidine hydrochloride was the most influential parameter in this study (OR 3.44, $95 \% \mathrm{Cl} 1.51-7.81, P<0.01)$. In general, benzodiazepines and opioids are typically utilized for sedation in gastrointestinal endoscopy [20]; however, for this study, flunitrazepam and/or pethidine hydrochloride were administered as a means of sedation. Benzodiazepines and particularly opioids [20] reportedly carry risks of respiratory and hemodynamic depression $[20,21]$. Based on these results, we propose a dosage reduction for pethidine hydrochloride when administered to very elderly patients. Alternatively, unsedated endoscopy has been suggested as an option to avoid complications in this cohort [22]. 
Some previous reports $[15,17]$ have highlighted the high diagnostic yield of endoscopy in the elderly. Our results indicate that the very elderly receive therapeutic interventions subsequent to routine endoscopy. This suggests that endoscopy appears to be an effective surveillance modality in the elderly population. However, it remains inconclusive whether endoscopy improves prognosis in this population. Large-scale observational studies to evaluate the efficacy of endoscopy and prognosis in the very elderly will help to elucidate this unanswered question.

\section{Conclusion}

In conclusion, the very elderly cohort received more therapeutic interventions proceeding routine endoscopy as compared to the younger group. Moreover, routine endoscopy in the very elderly carries increased risk of AEs, especially with concomitant use of pethidine hydrochloride sedation.

\section{Competing interests}

None

\section{References}

[1] Statistics Bureau, Ministry of Internal Affairs and Communications. Japan Statistical Yearbook 2017. http://www.stat.go.jp/english/data/ nenkan/index.htm

[2] World Health Organization. World Health Report 2013. http://www. who.int/whr/2013/report/en/

[3] Chukmaitov A, Siangphoe U, Dahman B et al. Patient Comorbidity and Serious Adverse Events after Outpatient Colonoscopy: Populationbased Study From Three States, 2006 to 2009. Dis Colon Rectum 2016; 59: 677-687

[4] Karajeh MA, Sanders DS, Hurlstone DP. Colonoscopy in elderly people is a safe procedure with a high diagnostic yield: a prospective comparative study of 2,000 patients. Endoscopy 2006; 38: 226-230

[5] Arora A, Singh P. Colonoscopy in patients 80 years of age and older is safe, with high success rate and diagnostic yield. Gastrointest. Endosc 2004; 60: 408-413. https://seer.cancer.gov/csr/1975_2014/browse_csr.php

[6] Howlader N, Noone AM, Krapcho M et al. National Cancer Institute. SEER Cancer Statistics Review(CSR) 1975-2014; https://seer.cancer. gov/csr/1975_2014/
[7] Buri L, Zullo A, Hassan C et al. Upper gastrointestinal endoscopy in elderly patients: predictive factors of relevant endoscopic findings. Intern. Emerg Med 2013; 8: 141 - 146

[8] Horiuchi A, Nakayama Y, Tanaka $\mathrm{N}$ et al. Propofol sedation for endoscopic procedures in patients 90 years of age and older. Digestion 2008; 78: $20-23$

[9] Qureshi WA, Zuckerman M], Adler DG et al. ASGE guideline: modifications in endoscopic practice for the elderly. Gastrointest Endosc 2006; 63: 566 - 569

[10] Zafar HM, Harhay MO, Yang J et al. Adverse events following computed tomographic colonography compared to optical colonoscopy in the elderly. Prev. Med. Rep 2014; 1: 3-8

[11] Adachi W, Yazawa K, Owa M et al. Quantification of cardiac stress during EGD without sedation. Gastrointest Endosc 2002; 55: 58-64

[12] Benson ME, Byrne S, Brust D] et al. EUS and ERCP complication rates are not increased in elderly patients. Dig Dis Sci 2010; 55: 3278 3283

[13] Lukens F], Loeb DS, Machicao VI et al. Colonoscopy in octogenarians: a prospective outpatient study. Am J Gastroenterol 2002; 97: 1722 1725

[14] Lee TC, Huang SP, Yang JY et al. Age is not a discriminating factor for outcomes of therapeutic upper gastrointestinal endoscopy. Hepatogastroenterology 2007; 54: 1319-1322

[15] Arora G, Mannalithara A, Singh G et al. Risk of perforation from a colonoscopy in adults: a large population-based study. Gastrointest Endosc 2009; 69: 654-664

[16] Ma WT, Mahadeva S, Kunanayagam S et al. Colonoscopy in elderly Asians: a prospective evaluation in routine clinical practice. J Dig Dis 2007; 8: 77-81

[17] Clarke GA, Jacobson BC, Hammett RJ et al. The indications, utilization and safety of gastrointestinal endoscopy in an extremely elderly patient cohort. Endoscopy 2001; 33: $580-584$

[18] Schmilovitz-Weiss H, Weiss A, Boaz $M$ et al. Predictors of failed colonoscopy in nonagenarians: a single-center experience. J Clin Gastroenterol 2007; 41: 388-393

[19] Day LW, Kwon A, Inadomi JM et al. Adverse events in older patients undergoing colonoscopy: a systematic review and meta-analysis. Gastrointest Endosc 2011; 74: 885-896

[20] Moon SH. Sedation regimens for gastrointestinal endoscopy. Clin Endosc 2014; 47: 135- 140

[21] Manolaraki MM, Theodoropoulou A, Stroumpos C et al. Remifentanil compared with midazolam and pethidine sedation during colonoscopy: a prospective, randomized study. Dig Dis Sci 2008; 53: 34-40

[22] Abraham NS, Fallone CA, Mayrand S et al. Sedation versus no sedation in the performance of diagnostic upper gastrointestinal endoscopy: a Canadian randomized controlled cost-outcome study. Am J Gastroenterol 2004; 99: 1692-1699 